\title{
Empirical Research on the Influence of International Crude Oil price fluctuation on Russian Exchange Rate
}

\author{
Qingyao $\mathrm{Li}^{*}$ \\ School of Finance, Xinjiang University of Finance and Economics, China
}

\begin{abstract}
Oil is a kind of basic energy and has close relationship with the financial markets. Russia is the world crude oil exporter, whose rich energy resources make the country tend to invest in energy industry and make policies for it. This has led to the fact that its national economic structure is too simplified and its economy is heavily dependent on the oil industry. The total oil exports for Russia each year account for up to forty percent of its fiscal revenues. The economic characteristics of Russia and the fluctuation of international crude oil price greatly influence the macroeconomic changes of a country and therefore the exchange rate will make a change too. So this paper, will explore the relationship between the international oil price and Russian exchange rate and the degree of the influence between each other. The paper will select international crude oil price as exogenous variables and take the Russian currency as endogenous variables to establish VAR model. In view of the conclusion, this paper points out the drawbacks of Russia's current economic development, and finally puts forward reasonable and effective suggestions from the aspects of exchange rate system and economic structure.
\end{abstract}

\section{Introduction}

Domestic and foreign research on the correlation between crude oil price and exchange rate [1] Junling Zhang and Weixian Wei (2017) used the dynamic GTAP model to simulate the transmission effect of the double impact of international oil price fluctuation and RMB devaluation on the macro economy. Empirical results show that international oil price fluctuations will have a greater impact on national macroeconomic. [2 ]Yu Wang and Da $\mathrm{Wu}(2017)$ selected data of several oil-producing countries as samples to list their exchange rate policies and make comparisons. Under the background of fluctuations in international crude oil prices, the main factors affecting the selection of exchange rate policies of sample oil-producing countries include the foreign exchange reserves of a country and the degree of national economy's dependence on oil.[3]Siqing Zhuo,Bo Wang and Lu Qiao (2017) used the Coupla function model as the framework to study the influence relationship between changes in international crude oil prices and Russia's real exchange rate. The conclusion shows that there is a strong left-right tail dependence between the two variables, which proves

* Corresponding author: 1272679496@qqq.com 
that the sharp fluctuation of Russian exchange rate in recent years is largely caused by the drastic fluctuation of international oil price.[4]Xi Zhang (2011) used co-integration analysis, concluded that the international crude oil price was a significant financial influence factor on the RMB exchange rate, and would also have an impact on the domestic fuel industry and its related products.[5]Yi Zhang,Ke Wang and Lin Jiang (2014) introduced three variables, namely OECD commercial inventory level, US industrial output coefficient and federal funds rate, and they finally reached a conclusion: the US dollar exchange rates had different degrees of influence on oil price in different periods.

In the existing studies, most of scholars mainly focus on the relationship between the rising international crude oil prices and the economic changes happening several years ago, Among them, the amount of theories is more than quantitative analysis on the relationship between the two factors and the conclusion mostly certifies that international oil prices to a certain extent will lead to the rising production cost for most of processing industry.It is predicted that the unemployment rate will increase and therefore inflation will follow. In that case, their economic growth will be hindered and with the degree of trade globalization increasing, it will make the adverse effect spread among nations. Moreover, most of the studies focus on the impact on the US dollars, major developed countries and the macro economy of RMB while there is little research on Russia, a big oil producer in the developing world. However, the situation of ruble depreciation and inflation caused by the sharp drop in oil prices since 2014 contradicted many verdicts. Therefore, in order to explore the relationship between oil price and exchange rate and the degree of mutual influence, this paper establishes VAR model.

\section{Model construction and data sources}

\subsection{Model construction}

Eviews 7.2 was used to carry out empirical research on 109 samples of relevant data from 2010 to 2019. Two variables were adopted: explanatory variable, International crude oil price OP, and explained variable, Russian Real effective exchange rate EX. In order to reduce heteroscedasticity-autocorrelation and increase the stability of the sequence, the logarithm of variable data was used to establish the following Var model:

$$
\begin{gathered}
\ln E X_{t}=C_{1}+\sum_{i=1}^{q} \boldsymbol{\alpha}_{i} \ln E X_{t-i}+\sum_{i=1}^{p} \boldsymbol{\beta}_{\boldsymbol{i}} \ln O P_{t-i}+\cdots+u_{1 t} \\
\ln O P_{t}=C_{2}+\sum_{i=1}^{p} \boldsymbol{\theta}_{i} \ln E X_{t-i}+\sum_{i=1}^{q} \boldsymbol{\gamma}_{i} \ln O P_{t-i}+\cdots+u_{2 t}
\end{gathered}
$$

Where, C_1 、C_2 are the constant terms, u_1t 、 u_2t are the independent white noise sequences, and $\alpha \_i, \beta \_i_{-}, \theta_{-}, \gamma_{-} i$ are the coefficient of vectors. These significance represent the correlation between vectors, and $\mathrm{i}$ is the lag order.

\subsection{Description of variables}

Russia belongs to the territory of Europe. The price of domestic Urals crude oil depends on the trading price of British Brent crude oil, so the price of Brent crude oil is used to replace the international crude oil price. The price of Brent crude oil is an independent variable determined by the model.The Russian real effective exchange rate represents the Russian exchange rate. This variable can more accurately measure the purchasing power of a country's currency after excluding the factor of inflation, and the data are easier to search, thus establishing a stable external reference condition for the model. 
Monthly data of Brent crude oil price is based on the closing price of Brent Futures Index in Sina Finance and Economics from November 2010 to the end of November 2019. Monthly data on the Russian real effective exchange rate are collected at the end of each month for the same period in Eurostat.

\section{Empirical analysis}

\subsection{ADF test}

The purpose of studying time series is to obtain information from historical data. Data stabilization represents time translation invariant to some extent. ADF test determines whether unit root exists in a sequence.The logarithmic transformation of the original data represents the change rate of each variable in the constructed model, which has its research significance. Meanwhile, heteroscedasticity and autocorrelation are reduced to increase the stationarity of the sequence.As shown in Table 1 , the sequence $\ln (\mathrm{OP})$ is unstable, while $\ln (\mathrm{EX})$ is stationary. However, if these variables are taken as first-order differences containing constant terms, two groups of stationary sequences can be obtained.In addition, after the regression, the residual sequence was extracted for the same test, and it was found that the stationary sequence represented the co-integration relationship between variables, namely, the long-term equilibrium relationship.

Table 1. ADF test of international oil price and Russian exchange rate.

\begin{tabular}{ccccc}
\hline Variable & Inspection form & The t-statistics & Prob.* & The results \\
\hline in $(\mathrm{EX})$ & trend and intercept & 3.479530 & 0.0468 & smooth \\
$\operatorname{dln}(\mathrm{EX})$ & intercept & -7.314090 & 0.0000 & smooth \\
$\ln (\mathrm{OP})$ & intercept & 1.488626 & 0.5357 & not smooth \\
$\operatorname{dln}(\mathrm{OP})$ & intercept & 8.299678 & 0.0000 & smooth \\
$e_{i}^{2}$ & intercept & 3.822767 & 0.0037 & smooth \\
\hline
\end{tabular}

Note: $\mathrm{Dln}(\mathrm{EX})$ is the first difference of $\operatorname{Ln}(\mathrm{EX})$

\subsection{Granger test}

Since these two time series are not integral of the same order, Granger test is conducted on the variables after the simultaneous first-order difference. The test results in Table 2 below show that DLN (EX)- DLN (OP) is true, and DLN (OP)- DLN (EX) is also true.That is, $\mathrm{P}<0.05$ rejects the null hypothesis and there is a bidirectional Granger causality, indicating that the rate of change of international oil price and the rate of change of Russian real exchange rate can respectively explain the change of each other.

Table 2. Granger causality test of the impact of the rate of change in international crude oil prices on the rate of change in Russian exchange rate.

\begin{tabular}{ccc}
\hline The null hypothesis & F-statistic & Prob. \\
\hline $\mathrm{D} \ln (\mathrm{OP})$ does not Granger cause $\operatorname{Dln}(\mathrm{EX})$ & 3.95654 & 0.0222 \\
$\mathrm{D} \ln (\mathrm{EX})$ does not Granger cause $\operatorname{Dln}(\mathrm{OP})$ & 4.36725 & 0.0152 \\
\hline
\end{tabular}

\subsection{The determination of the optimal lag order}

According to the test results of the stability of the above data, the first-order difference of two variables $\ln (\mathrm{EX})$ and $\ln (\mathrm{OP})$ can be studied empirically by using the vector autoregression model. Q criterion and SC criterion select the optimal lag order as the first order, while F statistic criterion and AIC information criterion select the third order as the best. Moreover, because the number of samples is large, the third 
order lag will not cause serious loss to the data. Therefore, the comprehensive evaluation decides to select the optimal lag order $\mathrm{P}=3$ to build the VAR(3) model.

\subsection{Impulse response}

When the stationarity of the VAR (3) model was measured, it was found that all points were obviously located in the unit circle, indicating that the VAR model was stable. Based on this premise, the impulse response was established as shown in the figure below to obtain the following conclusions.

In Figure 2, it can be seen from the impulse response of DOP to DEX that DLN (OP) gives a positive impact in the first phase and reaches the maximum impulse response value of 0.008 in the third phase. Then it goes negative in phase 4 , reaches its maximum in reverse in phase 5 , and then gradually approaches 0 . This indicates that after the international oil price shock, the real exchange rate of Russia had a significant positive impact before the fourth period, reflecting a small depreciation, but the positive impact only lasted for four periods.

From the impulse response of DEX to DOP in Figure 3, it can be seen that when $\ln (\mathrm{EX})$ gives $\ln (\mathrm{OP})$ a positive impact, the impulse response value of the rate of change of international oil price reaches the maximum value of 0.026 in the second phase, and then starts to continue the negative impact, and gradually shrinks back to 0 point after reaching 0.09 in the fifth phase. This means that the positive impact of the rate of change of the Russian exchange rate on the rate of change of the international oil price has a shorter duration than the effect of the oil price on the real exchange rate, but the impact of the rate of change of the oil price has a greater impact on the rate of change of the rouble exchange rate.

Figure 1 and Figure 4 respectively show the impulse response function of the rate of change of exchange rate of Russia and the rate of change of international oil price to itself. It can be seen that in the first phase, the impulse response of $D \ln (E X)$ to itself reached the maximum value, which was 0.33 , and then gradually moved to -0.09 . Finally, the impulse effect disappeared. The rate of change of international oil price has a positive impact on itself in the first stage as high as 0.72 , and then fluctuates in a small range around 0 from the fourth stage.

On the whole, the trend of the real exchange rate fluctuation of Russia is a small depreciation followed by a small appreciation. The reason may be that at the beginning, due to the impact of the international oil price, the total export of Russian crude oil declined rapidly while the import elasticity was relatively small. The rising inflation made the exchange rate fluctuation in previous periods intensified and led to depreciation. After the impact, the international demand for oil increased, the export recovered gradually, and the real exchange rate appreciated. Russia's currency for Brent oil prices is slightly greater than the influence of oil prices on the impact of exchange rate. It may be due to the fact that Russia is a energy giant in its oil reserves, production, export and transit and it plays a role in the international petroleum import and export pattern and pricing mechanism, so in the short term, Russia's real exchange rate fluctuations impact results are shown in the process in which the oil prices first rise and then fall. 


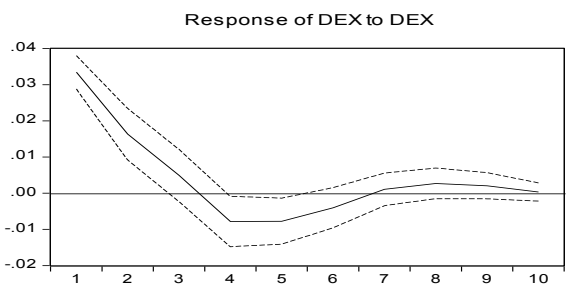

Fig. 1. Response of DEX to DEX.

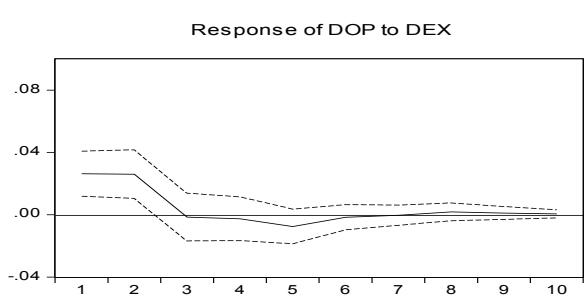

Fig. 3. Response of DOP to DEX.

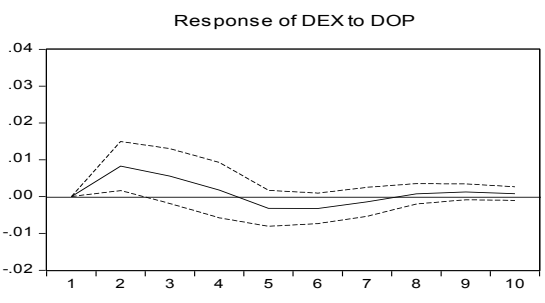

Fig. 2. Response of DEX to DOP.

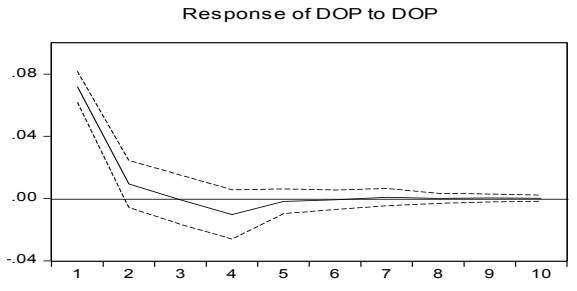

Fig. 4. response of DOP to DOP.

\section{Conclusions and suggestions}

\subsection{Conclusion}

Observation of the above empirical analysis results can be summarized as follows: First, the ADF test shows that the first-order difference between the international crude oil price and the Russian exchange rate is stable and there is a long-term equilibrium relationship between the original series. Second, Granger causality test shows that one of the changes in the international crude oil price and the Russian exchange rate can explain part of the changes in the other side. Finally, the impulse response results show that in the short term, the impulse response effect of the international oil price on the real exchange rate of Russia lasts longer, but the rouble exchange rate can have a greater shock on the international oil price.

Russia is a typical energy-dependent exporting country, with oil exports accounting for about 40 percent of its national revenue each year.Therefore, the changing factors in the international economic environment are more likely to make the rouble exchange rate fluctuate. When the international oil price is high, the rouble exchange rate will be stable, which may lead to a slight appreciation. When international events lead to lower oil prices, the depression of the price will often lead to drastic fluctuations and sharp drops in the rouble exchange rate.It can also be observed from the annual chart that the rise and fall of crude oil export prices and rouble exchange rate fluctuations show a more obvious consistency. The empirical evidence shows that the crude oil price has a strong correlation with the exchange rate of Russia, which also reflects the disadvantages of Russia's economic structure, raw materials, excessive dependence on the oil industry, resulting in the lack of innovative impetus for economic development;At this time, if the international situation is severe and the demand for oil imports decreases, then Russia's foreign exchange income will greatly reduce and it may also be accompanied by a large amount of capital flight, the rouble will face a substantial depreciation.Due to the lack of internal impetus, Russia's economic growth is gradually slowing down, and its investment and consumption income is also declining. As a result, its economic development is in a severe situation, which will adversely affect its trade with other countries. 


\subsection{Suggestions}

\subsubsection{Fluctuations in international oil prices sometimes have a positive impact}

Now Russia is in the period of oil war, it needs to gradually consolidate and expand its position in the international crude oil market and increases its competitiveness in the crude oil market, for example, it should compete for the share of exporting crude oil to powerful countries such as China so as to improve its energy status and achieve rapid economic development within a certain period of time.

\subsubsection{Use a more flexible exchange rate policy}

Russia started to implement the floating exchange rate system earlier. In most cases, considering the stability of the exchange rate, the Russian Central Bank would actively intervene in the foreign exchange market to minimize the exchange rate risks. It should try to use a more flexible exchange rate mechanism to achieve the market-oriented exchange rate mechanism and enhance the exchange rate flexibility, so as to prevent and defuse risks brought by financial factors to the country.

\subsubsection{Use a more flexible exchange rate policy Adjust industrial structure and accelerate economic transformation}

Russia should move faster to get rid of the resource-based development model, limit the export of national resources, actively adjust the industrial structure, and shift from relying on imports to substituting imports.In addition, the national income can be invested in the research and development of high-tech products and applications so as to enhance the scientific research level and manufacturing capacity of relevant enterprises and improve the way of national life and consumption.Investment in education and research should be increased, The country should also improve the competitiveness based on intelligence and knowledge and fundamentally foster its innovation capacity to increase its soft power.In addition, capital can be used in strategic investment, industrial resources can be integrated and gathered together to improve the efficiency of capital allocation.

\section{References}

1. Z Junling, W Weixian, The Impact of International Oil Price and RMB Exchange Rate Fluctuations on China's Economy -- the basis of Global General Equilibrium Analysis, Chinese Population Resources and Environment, S1,303-306(2017)

2. W Yu, W Da, Selection and Comparative Study of Oil-producing Countries' Exchange rate Policies under the Impact of International Oil Prices, Southern Finance, 12,5259(2017)

3. Z Siqing, W Bo and Q Lu, Research on the Impact of International Oil Price Fluctuations on Russia's Real Effective Exchange Rate, Price Theory and Practice, 01,82-85(2017)

4. Z Xi, Impact of International Crude Oil Price on Domestic Oil Price -- Based on the Pass-through Path of RMB Exchange Rate Fluctuation, Journal of Hebei University, 06,94-99(2011)

5. Z Yi, W Ke and J Lin, Correlation Analysis between US Dollar Exchange Rate and International Oil Price Trend, International Petroleum Economics, 05, 55-63 (2014) 